Nevşehir Bilim ve Teknoloji Dergisi Cilt 4(1) 88-96 2015

DOI: 10.17100/nevbiltek.210943

URL: http://dx.doi.org/10.17100/nevbiltek.210943

\title{
AISI 4140 Çeliğinin Çeşitli Çift Fazlı Mikroyapılarında Mekanik Özellikleri İle Sürtünme Davranışı İlişkisinin İncelenmesi
}

\author{
Mehmet Emin TAŞDELEN ${ }^{1, *}$, Hasan YEŞİLYURT ${ }^{2}$ \\ ${ }^{1}$ Erciyes Üniversitesi Mühendislik Fakültesi Malzeme Bilimi ve Mühendisliği Bölümü, Kayseri \\ ${ }^{2}$ Melikşah Üniversitesi Mühendislik ve Mimarlık Fakültesi, Makine Mühendisliği Bölümü, Kayseri \\ Öz
}

Çift fazlı çelikler otomotiv sektöründe ihtiyaç duyulan hafif ve dayanıklı malzeme ihtiyacını gidermek amacıyla ilk olarak 1970’li yıllarda geliştirilmişlerdir. Bu tür çelikler ferrit fazı içerisinde dağılmış halde yer alan martenzit fazının varlığı ile yüksek süneklik ve yüksek mukavemeti bir arada sunabilmektedirler. Isıl işlem parametreleri doğru olarak seçildiğinde birçok çelik türü için çift fazlı mikroyapının elde edilmesi mümkündür. Bu çalışmada AISI 4140 çeliğinden hazırlanmış çubuklar kritik sıcaklıklar arası tavlanma işlemini takip eden izotermal dönüşümlere tabi tutularak benzer sertlik değerlerinde çeşitli çift faz mikroyapılarına sahip numuneler elde edilmiştir. Bu numunelerin çekme, darbe dayanımı ve sertlik gibi mekanik özellikleri deneysel olarak belirlenmiş, ayrıca benzer sertlik değerlerine sahip bu yapıların aşınma davranışları incelenmiştir. Bu sonuçlar normalize AISI 4140 çeliğine ait sonuçlar ile karşılaştırılmıştır. Çift fazlı mikroyapı sayesinde benzer sertlik değerleri için daha tok ve sürtünme katsayısı düşük çeliklerin üretilebileceği fakat bunun aşınma nedeniyle oluşan kütle kaybına bir katkısı olmadığı görülmüştür.

Anahtar kelimeler: Çift fazlı çelik, mekanik özellik, sürtünme davranışı, aşınma.

\section{Investigation of the Relation Between Mechanical Properties and Frictional Behavior of Dual Phase AISI 4140 Steel}

\begin{abstract}
Dual phase steels were developed firstly in 1970's in order to provide of light and strength materials for automobile industries. Since the presence of distributed martensite phase in the matrix of ferrite phase, these type of steels can be provide both high ductility and high strength in a materials together. Obtaining a dual-phase microstructure for many types of steel is possible by the selection of heat treatment parameters properly. In this study, steel bars prepared from AISI 4140 steel were subjected to some thermal treatment followed by isothermal transformation and various dual phase microstructure in similar hardness specimens were obtained. Some mechanical properties such as impact strength, and hardness of these materials were identified, in also wear behavior of these materials which were in similar hardness is investigated. These results are compared with those of AISI 4140 steel. As a result it seen that with dual phase microstructure it can be produced a materials with more toughness and low friction coefficient, but those properties does not affect the weight loss occurring due to wear.
\end{abstract}

Keywords: Dual phase steel, mechanical properties, friction behavior, wear.

*e-mail: metasdelen@erciyes.edu.tr,$\underline{\text { metasdelen@gmail.com }}$ 


\section{Giriș}

Isıl işlem; malzemeye katı halde uygulanan ve malzemenin mekanik özelliklerini değiştirmek için yapılan kontrollü ısıtma ve soğutma işlemlerini tanımlayan bir terimdir [1]. Yapılan bu işlemlerle amaç malzemenin mikroyapısını ve/veya mekanik özelliklerinin değiştirilmesidir. Birçok uygulamada 1sıl işlem ile genellikle daha iyi çekme mukavemeti, daha yüksek darbe tokluğu veya yüksek aşınma direnci gibi daha iyi mekanik özelliklerin elde edilmesi amaçlanır. Bununla birlikte pratikte bir malzemeye uygulanan 1sıl işlem o malzemenin birden fazla mekanik özelliğinin eş zamanlı olarak değişmesine sebep olur [2-4]. Örnek vermek gerekirse su verme işlemi ile çeliğin sertliği artarken aynı zamanda tokluk değerinde düşüş meydana gelmektedir.

Çift veya çoklu faz mikroyapısına sahip çelikler tok ve mukavemetli çeliklerin üretilmesi amacıyla geliştirilmişlerdir $[5,6]$. Bu tür çelikler çoğunlukla ısıl işlem süreçleri ile elde edilmektedir. Her ne kadar "çift faz" terimi yaygın olarak ferrit ve adacıklar halinde, hacimce yaklaşık \%10 - \%20 arasında martenzit fazlarının bir karışım halinde birlikte bulunması halini tarif etse de [7], artık günümüzde ferrit fazı ile birlikte bir başka fazın daha varlığını ifade etmek amacıyla kullanılmaktadır [8, 9]. Çift faz yapısı sayesinde iki veya daha fazla karakteristik malzeme özelliği bir tek malzemede aynı anda elde edilebilmektedir [10]. Mikroyapıyı oluşturan fazların miktarları ile malzemenin mekanik özellikleri arasında net bir ilişkinin var olduğu tartışılmaz bir gerçektir [11-13].

$\mathrm{Bu}$ çalışmada farklı çift faz 1sıl işlemlerine tabi tutulmuş AISI 4140 çeliğinden üretilen numunelerin çekme mukavemeti, sertlik değerleri, tokluk değerleri ve kopma uzamaları mekanik olarak test edilmiş, bu numunelerin aşınma davranışları incelenmiş ve normalize AISI 4140 numunesinin değerleri ile karşılaştırılmıştır. Normalizasyon işlemi sonrası AISI 4140 numuneleri ikili faz bölgesine erişmesi için $760{ }^{\circ} \mathrm{C}$ sıcaklıkta 60 dakika süre ile tavlanmıştır. Ardından ötektoid öncesi ferrit yapısı içerisinde dağılmış olarak farklı oranlarda ferrit, beynit ve diğer mikroyapıların elde edilmesi amacıyla tuz banyosuna alınarak izotermal dönüşüm sıcaklığı olarak belirlenen $345^{\circ} \mathrm{C}$ sıcaklıkta farklı sürelerde tutulmuştur.

\section{Deneysel Çalışma}

Çalışmada AISI 4140 çeliği kullanılmıştır, kullanılan malzemeye ait kimyasal kompozisyon Tablo 1'de görülmektedir. Tüm numuneler öncelikle $860{ }^{\circ} \mathrm{C}$ sıcaklıkta 45 dakika süre boyunca 1sitılıp, havada oda sıcaklığına kadar soğutularak normalize edilmiştir. Daha sonra malzemeler kritik sıcaklıklar arasındaki bölgede, $760^{\circ} \mathrm{C}$ sıcaklıkta tavlanmışlardır. İzotermal dönüşüm $345^{\circ} \mathrm{C}$ sıcaklıkta h1 numunesi için 15, h2 numunesi için 30 ve S4 numunesi için 120 dakika süre ile uygulanmıştır. İzotermal dönüşüm sonrası h1 ve h2 kodlu numuneler havada soğutulurken S4 kodlu numune suda soğutmaya tabi tutulmuştur. Uygulanan bu 1sıl işlemler Tablo 2'de özet olarak verilmektedir. Normalizasyon ve diğer tüm ısıl işlemler $20 \mathrm{~mm}$ çapında ve $300 \mathrm{~mm}$ uzunluğunda çubuklara uygulanmıştır. Çekme testi, darbe testi ve sürtünme deneyleri için gerekli numuneler bu çubuklardan talaşlı imalat yolu ile daha sonra elde edilmişlerdir. Sürtünme test numuneleri 1000'lik zımpara ile zımparalanmış ve parlatılmıştır. Isıl işlemler için kullanılan firınlarlar Şekil 1 ve Şekil 2'de görülmektedir. Çekme testleri için SHIMADZU AGXD50kN test cihazı kullanılmıştır, Şekil 3. Çentik darbe testleri, test standartlarına uygun olarak Charpy darbe test cihazı ile yapılmıştır, Şekil 4. 
Taşdelen ME., Yeşilyurt H.

Tablo 1. Çalışmada kullanılan AISI 4140 çeliğine ait kimyasal kompozisyon

\begin{tabular}{cccccccc}
\hline $\mathbf{C}$ & $\mathbf{M n}$ & $\mathbf{P}(\max )$ & $\mathbf{S}(\mathbf{m a x})$ & $\mathbf{S i}$ & $\mathbf{C r}$ & $\mathbf{M o}$ & $\mathbf{F e}$ \\
0,40 & 0,79 & 0,008 & 0,008 & 0,27 & 0,98 & 0,15 & Kalan \\
\hline
\end{tabular}

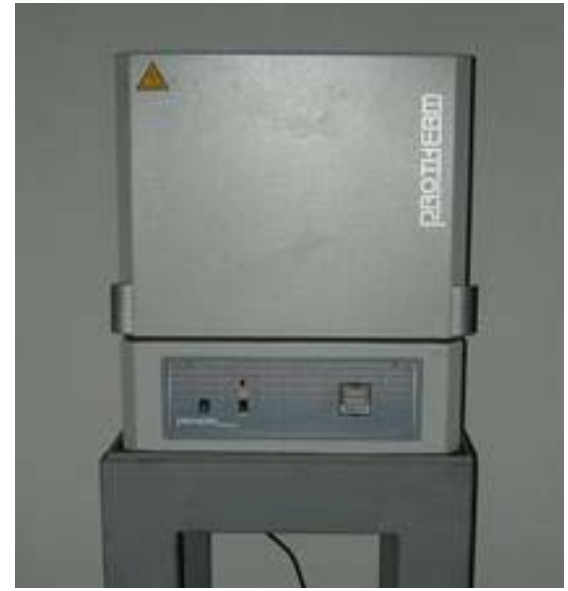

Şekil 1. Isıl işlem firını

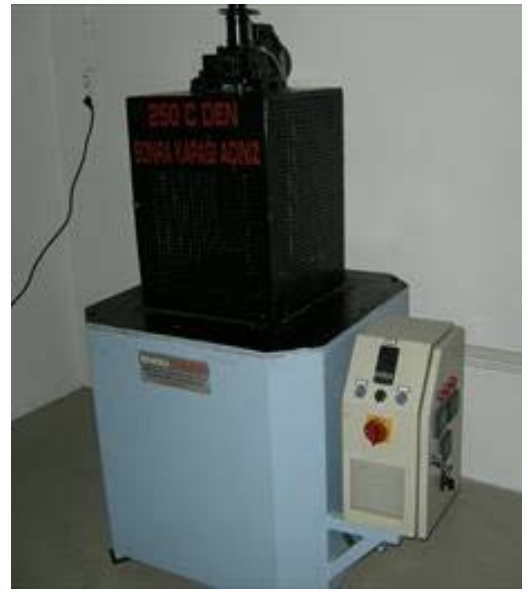

Şekil 2. Tuz banyolu 1 ssıl işlem sistemi

Tablo 2. Çalışmada uygulanan ısıl işlem süreçleri

\begin{tabular}{|c|c|c|}
\hline & Mikroyapı & Isıl İşıem \\
\hline h1 & $\begin{array}{l}\text { Beynit - \% } 24 \text { Ferrit }- \text { Kalınt1 } \\
\text { östenit }\end{array}$ & $\begin{array}{l}\text { Normalize } 860^{\circ} \mathrm{C}(45 \mathrm{dk}) \text {, temperleme } 760^{\circ} \mathrm{C} \quad\left(\begin{array}{lll}60 & \mathrm{dk}\end{array}\right) \text {, izotermal } \\
\text { transformasyon } 345^{\circ} \mathrm{C}(15 \mathrm{dk}) \text {, havada soğutma. }\end{array}$ \\
\hline h2 & $\begin{array}{l}\text { Beynit - \% } 24 \text { Ferrit }- \text { Kalınt1 } \\
\text { östenit }\end{array}$ & $\begin{array}{l}\text { Normalize } 860^{\circ} \mathrm{C}(45 \mathrm{dk}) \text {, temperleme } 760^{\circ} \mathrm{C} \quad\left(\begin{array}{lll}60 & \mathrm{dk}\end{array}\right) \text {, izotermal } \\
\text { transformasyon } 345^{\circ} \mathrm{C}(30 \mathrm{dk}) \text {, havada soğutma.. }\end{array}$ \\
\hline S4 & $\begin{array}{l}\text { Beynit - \% } 24 \text { Ferrit }- \text { Kalınt1 } \\
\text { östenit }\end{array}$ & $\begin{array}{l}\text { Normalize } 860^{\circ} \mathrm{C}(45 \mathrm{dk}) \text {, temperleme } 760^{\circ} \mathrm{C} \quad\left(\begin{array}{lll}60 & \mathrm{dk}\end{array}\right) \text {, izotermal } \\
\text { transformasyon } 345^{\circ} \mathrm{C}(120 \mathrm{dk}) \text {, suda soğutma. }\end{array}$ \\
\hline
\end{tabular}

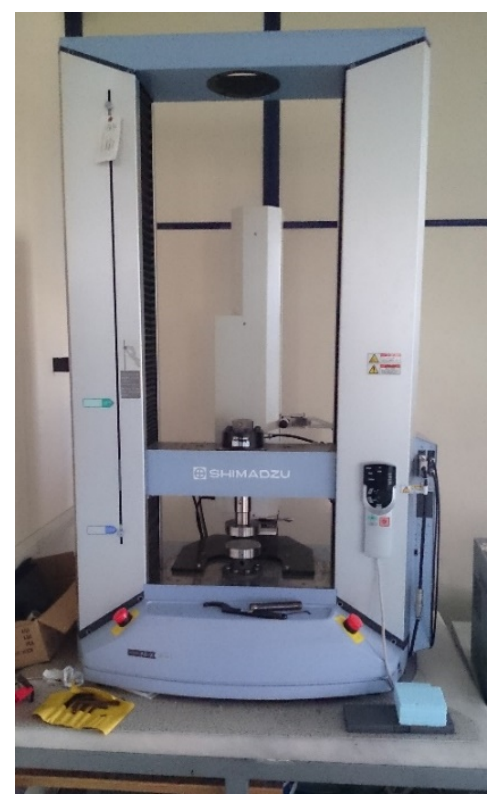

Şekil 3. Universal çekme testi cihazı

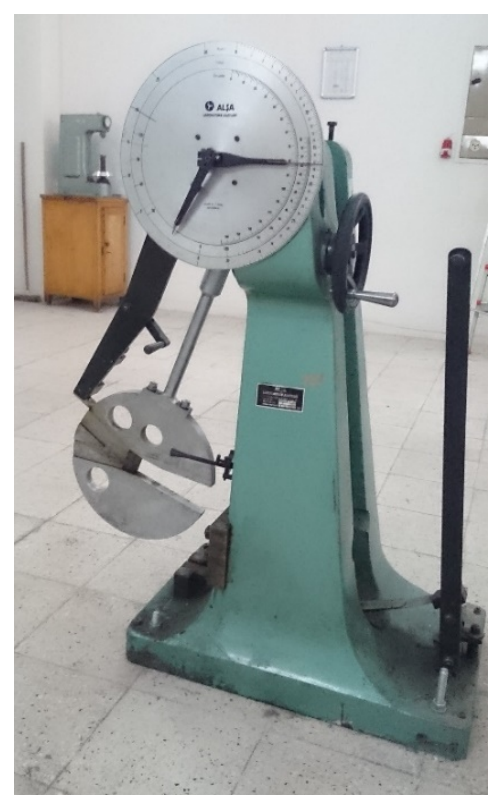

Şekil 4. Charpy çentik darbe test cihazı 
Aşınma testleri için kuru ortamda "ball-on-disc" kaymalı test yöntemi kullanılmıştır, Şekil 5. Isıl işlem uygulanmış numuneler, $\mathrm{Al}_{2} \mathrm{O}_{3}$ bilyalar ile teste tabi tutulmuşlardır. Testler kuru ortamda ve oda sıcaklığında 10, 20 ve $30 \mathrm{~N}$ yük altında, sabit $0.04 \mathrm{~m} \mathrm{~s}^{-1}$ kayma hızında gerçekleştirilmiştir. Testler toplam kayma mesafesi 500 metre olarak uygulanmıştır. Her bir test sonrası aşındırıcı bilye değiştirilmiştir.

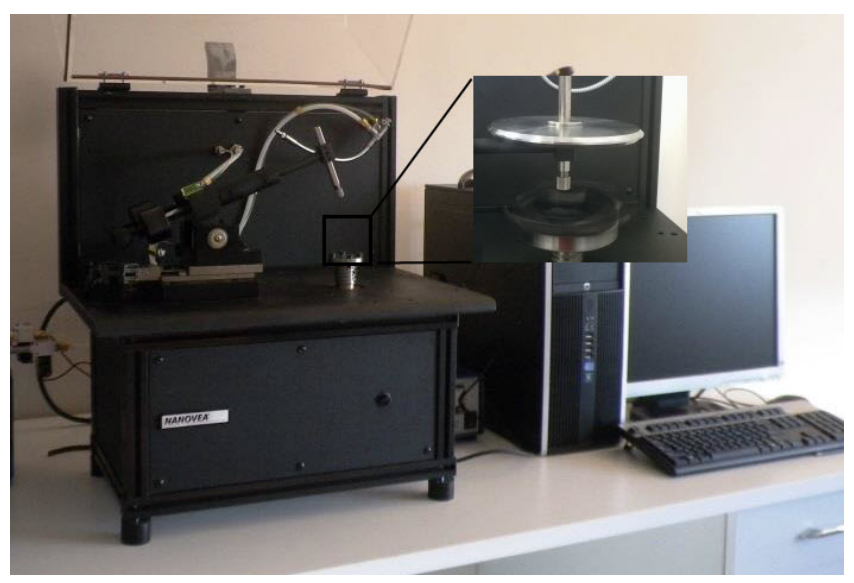

Şekil 5. Aşıınma test cihazı

\section{Test Sonuçları ve Değerlendirme}

a. Mekanik test sonuçları

Isıl işlem uygulanmış çubuklardan talaşlı imalat ile elde edilen numuneler çekme ve darbe testlerine tabi tutulmuş, ayrıca sertlik ölçümleri yapılmıştır. Normalize numune için ölçülen sertlik değeri literatür ile uyumlu bulunmuştur [14]. Sertlik değerleri arasında çift faz 1sıl işlemi nedeniyle önemli bir değişimin olmadığı açıkça görülmüştür, Tablo 3. Bununla birlikte normalize edilmiş numune ile kıyaslandığında h1 ve S4 numunelerinin sertlik değerlerinde az da olsa bir artışın olduğu görülmektedir, Tablo 3 .

Tablo 3: Numunelere ait tokluk ve sertlik testi sonuçları

\begin{tabular}{cccc}
\hline Malzeme & Numune & $\begin{array}{c}\text { Tokluk } \\
\left(\mathbf{k p m} / \mathbf{c m}^{2}\right)\end{array}$ & $\begin{array}{c}\text { Sertlik } \\
\text { (HRC) }\end{array}$ \\
& Normalize & 2.08 & 30.8 \\
$\frac{5}{2}$ & h1 & 12.54 & 32.2 \\
\hline
\end{tabular}

Öte yandan çekme mukavemetinde bir miktar düşme görülürken normalize edilmiş numune ile kıyaslandığında kopma uzamasında \%50 oranında bir düşüş olmuştur, Tablo 4 . 
Tablo 4: Numunelere ait çekme mukavemeti ve kopma uzaması değerleri

\begin{tabular}{cccc}
\hline Malzeme & Numune & $\begin{array}{c}\text { Çekme } \\
\text { Mukavemeti } \\
\text { (MPa) }\end{array}$ & $\begin{array}{c}\text { Kopma } \\
\text { Uzaması }\end{array}$ \\
$\mathbf{\%}$ \\
Normalize & 1003 & 16,24 \\
$\underset{+}{+}$ & h1 & 808 & 8,26 \\
$\frac{\vec{\sigma}}{\varangle}$ & h2 & 1030 & 7,58 \\
& S4 & 962 & 7,14 \\
\hline
\end{tabular}

\section{b. Mikroyapı}

Kritik sıcaklıklar arasında uygulanan 1sıl işlemin bir sonucu olarak h1, h2 ve S4 kodlu numunelerde ferrit ve beynit fazlarının karışımı halinde çift faz yapısı gözlemlenmiştir, Şekil 6. Görüntü işleme yazııımı ile gerçekleştirilen faz miktarı tayininde çift faz mikroyapılarının \% 24 oranında ferrit içerdiği belirlenmiştir. Buna ek olarak izotermal dönüşüm süresi ve dönüşüm sonrası soğuma şartlarına bağlı olarak yapıda kalıntı östenitin mevcudiyeti de bilinmelidir.

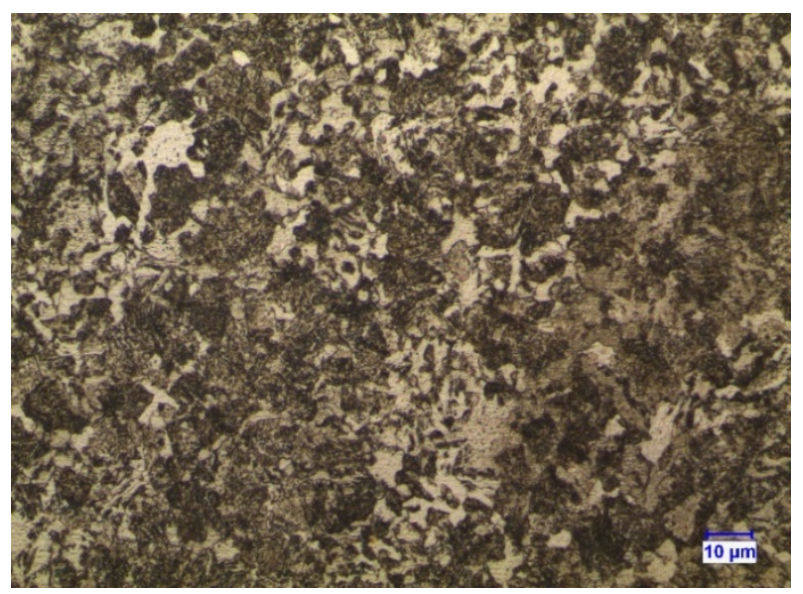

Şekil 6. h1 kodlu numunenin optik mikroskopta mikroyapı görüntüsü

\section{c. Aşınma Test Sonuçları}

Aşınma testleri tüm numuneler için 10, 20 ve $30 \mathrm{~N}$ yükleme ile kuru şartlar altında sabit hızla gerçekleştirilmiştir. Anlık olarak elde edilen sürtünme katsayısı ve kayma mesafesi bilgileri daha sonra grafiğe dönüştürülmüştür. Her bir test sonrasında numuneler tartılarak kütle kayıpları tespit edilmiştir. Şekil 7, Şekil 8 ve Şekil 9'da sırasıyla 10, 20 ve 30 N yük için kayma mesafesine bağlı olarak sürtünme katsayısının değiş̧imi verilmiştir. $10 \mathrm{~N}$ yüklemede eğriler yaklaşık $50 \mathrm{~m}$ kayma mesafesinden sonra rejime girerken, artan yüklemeye bağlı olarak bu mesafe 150 metreye kadar çıkabilmektedir.

Yakın sertlik değerlerine sahip olmalarına rağmen dört numunenin hepsinin de aynı yük seviyelerinde birbirinden farklı sürtünme katsayısı sergiledikleri görülmektedir. Düşük yük seviyesinde çift fazlı numuneler için daha az olan bu farklılık artan yük değeri ile daha belirgin hale gelmektedir. Bu durum ancak mikroyapıdaki farklılıklar ile izah edilebilir. İzotermal dönüşüm süresi ve sonrasındaki soğutma şartlarına göre özellikle kalıntı östenit miktarının değiştiği bilinmektedir [15]. Yeterli soğuma sağlanamadığı durumlar için sıfır altı sıcaklıklarda soğutma ile kalıntı östenitin varlığı 
engellenebilmektedir [16]. Özellikle h1 kodlu numunenin sürtünme katsayısının artan yüklemelerdeki düşüşünün mikroyapı içerisinde bulunan kalıntı östenitin gerilme etkisi ile martenzite dönüşümü sayesinde oluştuğu düşünülmektedir. Literatürde de bu olguyu destekler nitelikte çalışmalar mevcuttur [17]. İzotermal dönüşümün süresine ve dönüşüm sonrası soğuma şartlarına bağlı olarak mikroyapının değiştiği bunun da diğer mekanik özellikler ile birlikte sürtünme davranışını etkilediği düşünülmektedir. Özellikle yüksek yükleme değerlerinde, sertlik değeri aynı olmasına rağmen AISI 4140 çeliğinden üretilen numunelerde tokluk artışı ve düşük sürtünme katsayısının çift faz mikroyapısı ile elde edilebileceği görülmüştür.

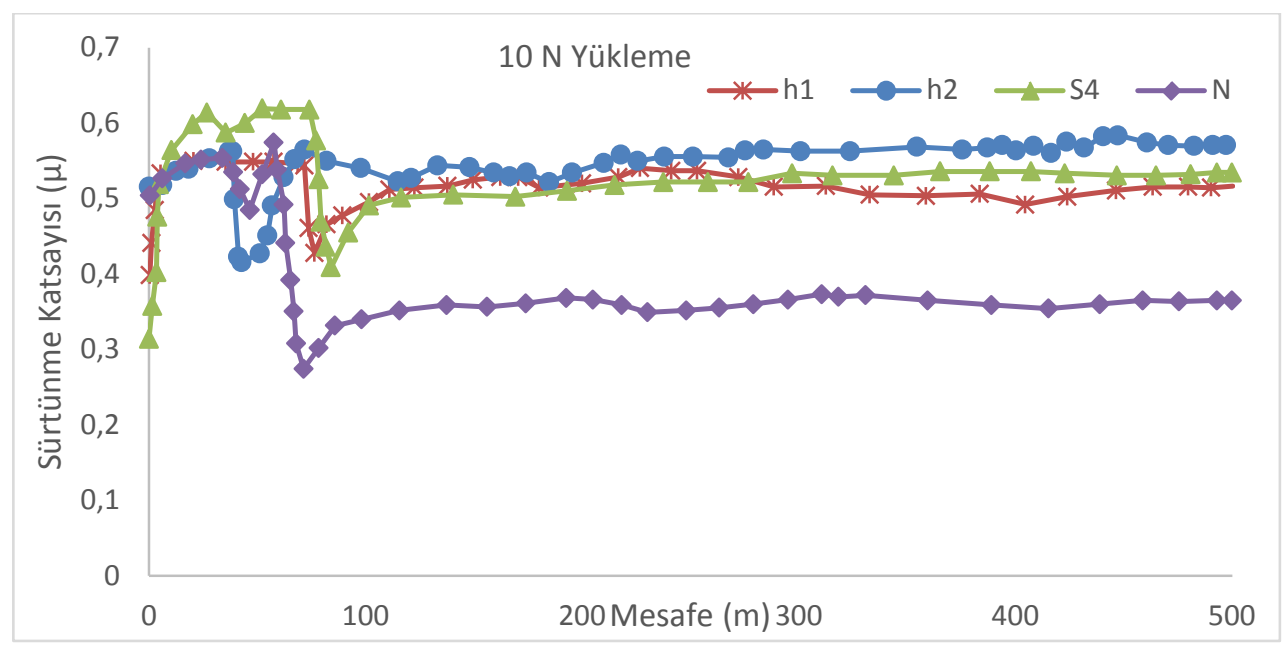

Şekil 7. 10 N yük değeri için kayma mesafesi - sürtünme katsayısı değişimi

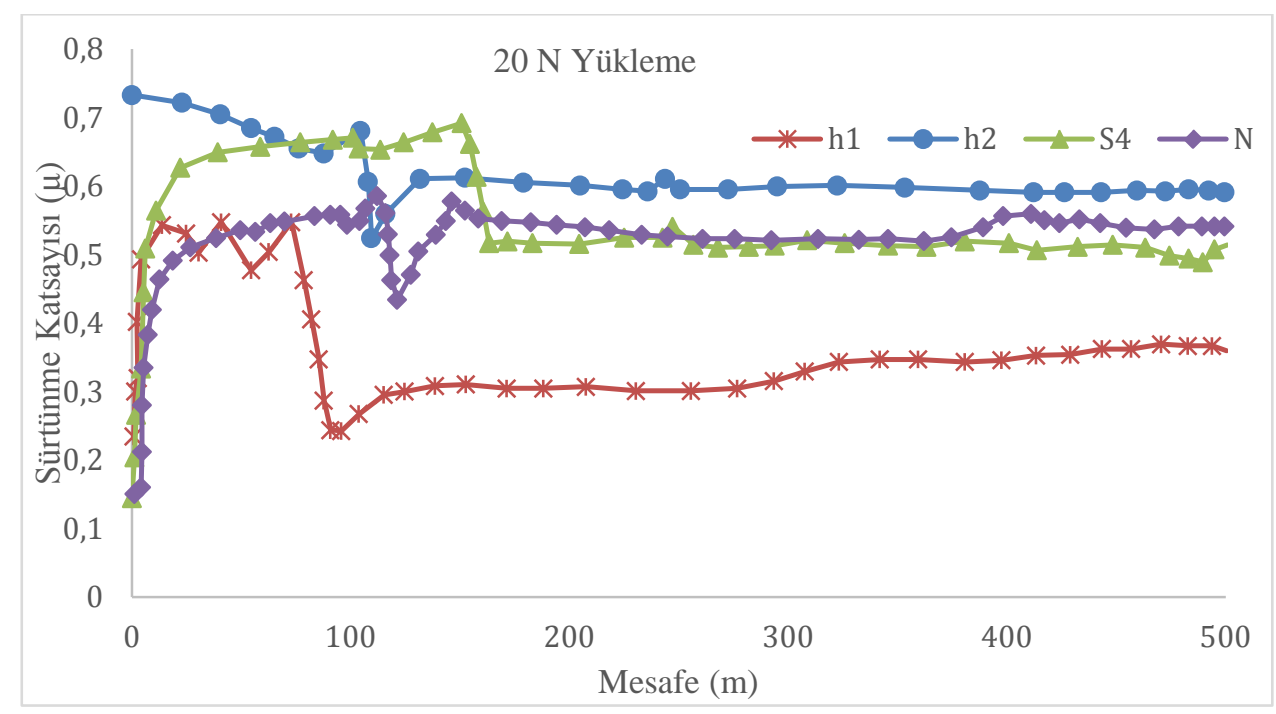

Şekil 8. 20 N yük değeri için kayma mesafesi - sürtünme katsayısı değişimi 
Taşdelen ME., Yeşilyurt $\mathrm{H}$.

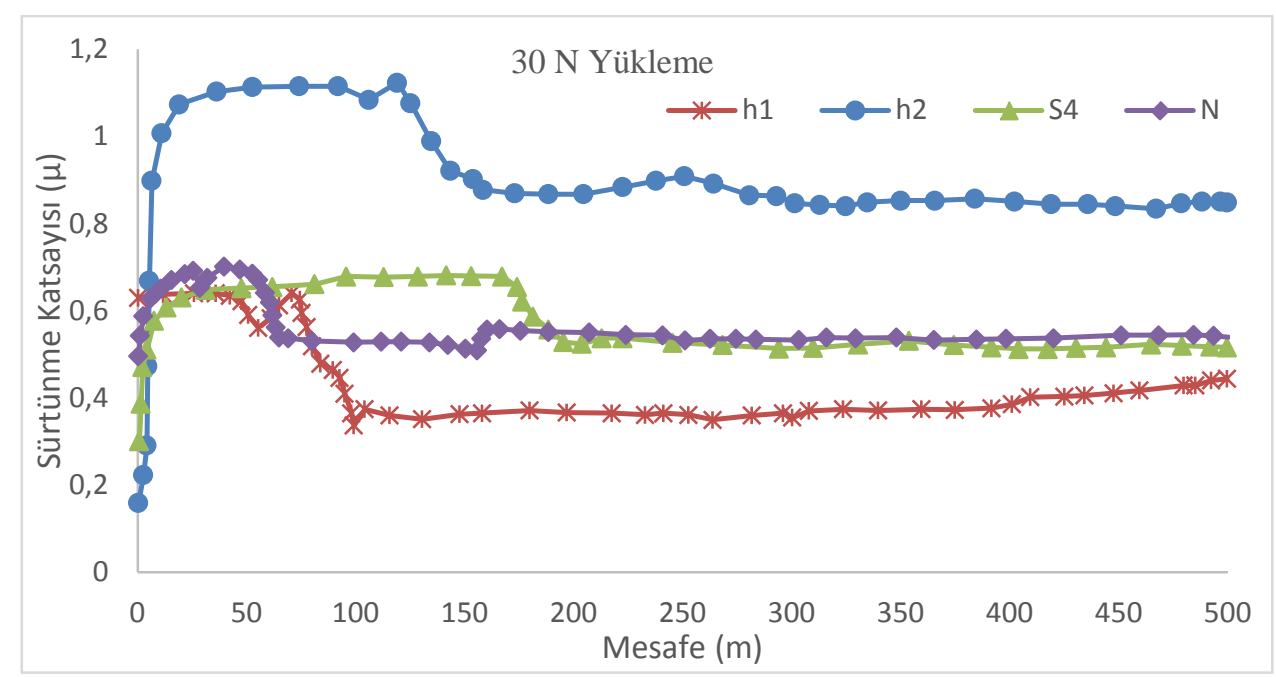

Şekil 9. $30 \mathrm{~N}$ yük değeri için kayma mesafesi - sürtünme katsayısı değişimi

500 metre olarak gerçekleştirilen aşınma testleri sonrasında yapılan kütle tartımları ile oluşturulan yük - kütle kaybı eğrileri incelendiğinde sürtünme katsayılarındaki sıralamanın aşınma miktarı ile aynı olmadığı görülmektedir. Şekil 10 ile verilen grafikte görüldüğü gibi, S4 ve N kodlu numunelerin sürtünme katsayıları $30 \mathrm{~N}$ yüklemede oldukça yaklaşık olmasına rağmen, aşınmaya bağlı kütle kaybında çok farklı bir sonuç ortaya çıkmaktadır. Buna ek olarak hem 20 hem de $30 \mathrm{~N}$ yük altında h1 kodlu numunenin sürtünme katsayısı N kodlu normalize edilmiş numunenin yarısı değerinde olmasına rağmen, kütle kaybı konusunda aynı oran korunamamıştır.

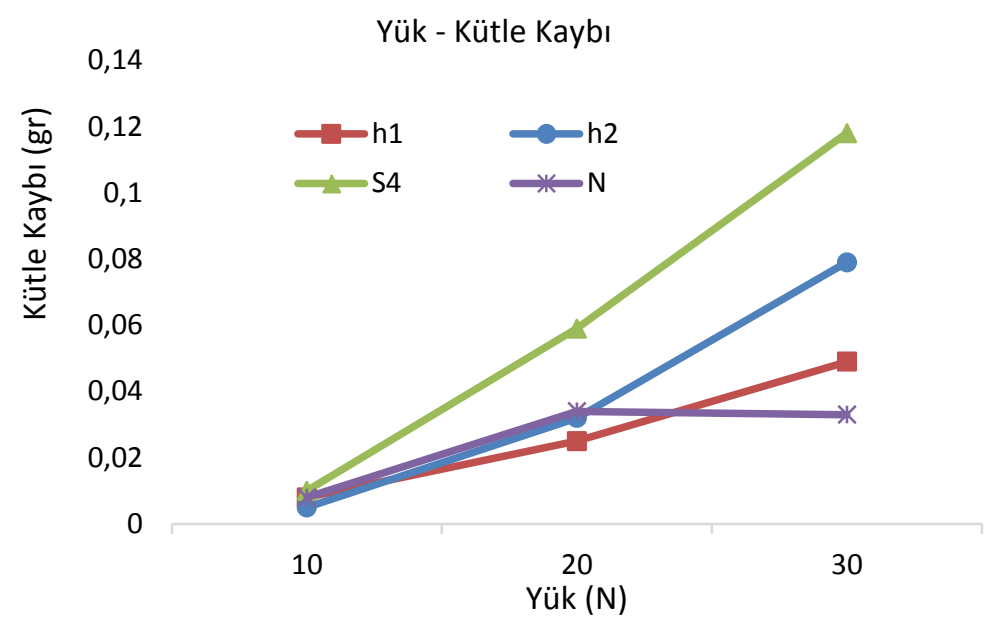

Şekil 10. 10, 20 ve 30 N yükleme durumunda numunelerde meydana gelen kütle kayıplar

\section{Sonuçlar}

Çalışma sonunda elde edilen bulgu ve sonuçlar şu şekilde sıralanabilir;

1. AISI 4140 çeliğinin uygun sıcaklık değerleri arasında tavlanması ve soğutulması ile ferrit ve beynit yapılarını içeren çift fazlı mikroyapıları elde edilebilir.

2. Kritik sıcaklıklar arasındaki $760^{\circ} \mathrm{C}$ sıcaklıkta yeterli bir süre boyunca tavlanma sonrası mikroyapı içerisinde hacimce yaklaşık olarak \%24 oranında ferrit fazı bulunmaktadır. 
3. AISI 4140 çeliğinin bazı çift fazlı mikroyapılarında aynı oranda ferrit fazı bulunmasına rağmen ikinci fazın oluşma şartları mikroyapıyı ve dolayısıyla mekanik özellikleri doğrudan etkilemektedir. Optik mikroskop altında benzer mikroyapı görünüşleri sergilemelerine rağmen kritik sıcaklık tavlamasını takiben uygulanan izotermal dönüşümün süresine ve sonrasında uygulanan soğutma şartlarına göre mekanik özellikler değişmektedir.

4. AISI 4140 çeliğinin bazı çift fazlı mikroyapıları ile benzer sertlik değerlerine sahip fakat tokluğu normalize haldekine kıyasla 3-5 kat daha fazla çelikler elde edilebilir.

5. AISI 4140 çeliğinin bazı çift fazlı mikroyapıları ile benzer sertlik değerlerine sahip fakat aşınma davranışları farklı çelikler elde edilebilir. Söz konusu malzemenin sürtünme katsayısı bazı çift fazlı mikroyapılarında normalize haldekine kıyasla daha düşük olmaktadır. Bununla birlikte sürtünme katsayısının azalmasına rağmen aşınma sonucu oluşan kütle kayıpları sürtünme katsayısına doğrudan bağlı olarak gerçekleşmemektedir.

6. AISI 4140 çeliğinin bazı çift fazlı mikroyapıları ile normalize edilmiş haline kıyaslandığında daha tok, benzer sertlikte, daha düşük sürtünme katsayısına sahip ve aşınma direnci benzer malzemeler elde edilebilmektedir.

7. AISI 4140 çeliğinin sürtünme davranışı uygulanan yükleme şartlarına göre değişiklik göstermektedir. Deneysel olarak uygulanan şartların teknolojik uygulamaya benzer şekilde yapılması sonuçların daha nitelikli olmasını sağlayacaktır.

\section{Kaynaklar}

[1] Krauss, G. and G. Krauss, "Steels: heat treatment and processing principles" Vol. 24. 1990: ASM international Materials Park, $\mathrm{OH}$.

[2] Tavares, S.S.M., et al., "Mechanical properties of a quenched and tempered dual phase steel" Scripta Materialia, 40(8): p. 887-892, 1999

[3] Chang, P.H., "Effects of prior tempering on the strain aging of a continuously annealed 0.05\% C dual phase steel" Scripta Metallurgica, 17(8): p. 1009-1014, 1983

[4] Grushko, B. and B.Z. Weiss, "Yield behaviour of dual-phase steel" Scripta Metallurgica, 23(6): p. $865-870,1989$

[5] Acarer, M. and B. Demir, "An investigation of mechanical and metallurgical properties of explosive welded aluminum-dual phase steel" Materials Letters, 62(25): p. 4158-4160, 2008

[6] Llewellyn, D. and D. Hillis, "Dual phase steels" Ironmaking \& steelmaking, 23(6): p. 471478, 1996

[7] Coldren, A.P. and G. Tither, "Development of a Mn-Si-Cr-Mo as-rolled dual-phase steel" JOM, 30(4): p. 6-9, 1978

[8] Akbarpour, M.R. and A. Ekrami, "Effect of ferrite volume fraction on work hardening behavior of high bainite dual phase (DP) steels" Materials Science and Engineering: A,. 477(1-2): p. 306-310, 2008

[9] Kumar, A., S.B. Singh, and K.K. Ray, "Influence of bainite/martensite-content on the tensile properties of low carbon dual-phase steels" Materials Science and Engineering: A, 474(1-2): p. 270-282, 2008 
[10] Liedl, U., S. Traint, and E.A. Werner, "An unexpected feature of the stress-strain diagram of dual-phase steel" Computational Materials Science, 25(1-2): p. 122-128, 2002

[11] Cai, X.-L., J. Feng, and W.S. Owen, "The dependence of some tensile and fatigue properties of a dual-phase steel on its microstructure" Metallurgical Transactions A, 16(8): p. 1405-1415, 1985

[12] Farabi, N., D.L. Chen, and Y. Zhou, "Microstructure and mechanical properties of laser welded dissimilar DP600/DP980 dual-phase steel joints" Journal of Alloys and Compounds, 509(3): p. 982-989, 2011

[13] Nakagawa, A.H. and G. Thomas, "Microstructure-mechanical property relationships of dualphase steel wire" Metallurgical Transactions A, 16(5): p. 831-840, 1985

[14] Vargas-Arista, B., et al., "Normalizing effect on fatigue crack propagation at the heat-affected zone of AISI 4140 steel shielded metal arc weldings" Materials Research, 16(4): p. 722-778, 2013

[15] Saleh, M.H. and R. Priestner, "Retained austenite in dual-phase silicon steels and its effect on mechanical properties" Journal of Materials Processing Technology, 113(1-3): p. 587-593, 2001

[16] Preciado, M., P.M. Bravo, and J.M. Alegre, "Effect of low temperature tempering prior cryogenic treatment on carburized steels" Journal of Materials Processing Technology, 176(1-3): p. 41-44, 2006

[17] Colaço, R. and R. Vilar, "On the influence of retained austenite in the abrasive wear behaviour of a laser surface melted tool steel" Wear, 258(1-4): p. 225-231, 2005 